\title{
Developing A Teacher Leadership Stance During the Practicum Experience
}

\author{
Youmen Chaaban', Rania Sawalhi' \\ ${ }^{1}$ Assistant Professor, Department of Education, Azm University, Lebanon, \\ ${ }^{2}$ Field Training Specialist, College of Education, Qatar University, Qatar
}

\begin{abstract}
:
This qualitative study investigated the nature of thirteen student teachers' development of a teacher leadership stance during their practicum experience. Data collection included pre-and post-interviews, weekly journals, classroom observations, and multiple assignments. Data analysis was carried out using deductive and inductive methods, using the conceptual framework of leadership views, leadership activities and leadership stance, but allowing for new analytical themes to emerge. Findings revealed three manifestations of a teacher leadership stance as participants engaged in leadership activities and changed their views about teacher leadership. Exploring the potential of a practicum experience with a focus on teacher leadership provided a nuanced understanding of possibilities and limitations, both personal and contextual. The study includes implications for the design of initial teacher preparation programs designed to prepare student teachers as teacher leaders.
\end{abstract}

Keywords: contextual factors; practicum experience; stance, student teachers, teacher leadership 